\title{
Functionalised $\mathrm{Mn}^{\mathrm{V}}$-nanoparticles: an advanced high-valent magnetic catalyst
}

SUBJECT AREAS:

ORGANIC-INORGANIC NANOSTRUCTURES

CATALYST SYNTHESIS

Received

10 November 2014

Accepted

16 January 2015

Published

2 March 2015

Correspondence and requests for materials should be addressed to

D.K.M. (dkmchem@ caluniv.ac.in)

\author{
Saikat Khamarui, Yasmin Saima, Radha M. Laha, Subhadeep Ghosh \& Dilip K. Maiti
}

Department of Chemistry, University of Calcutta, University College of Science, 92 A. P. C. Road, Kolkata-700009, India.

We discover $\mathrm{Mn}^{\mathrm{VI}}$-nanoparticles (NPs) bearing functional groups, high oxidation state, strong electron affinity, unique redox and paramagnetic nature, which opens up a new avenue to catalysis, magnetism and material application. However, its synthesis is challenging and remains unexplored because of associated serious difficulties. A simple benign synthetic strategy is devised to fabricate the high-valent NPs using mild reducing agent bromide, which transformed $\mathrm{Mn}^{\mathrm{VII}}$ to valuable $\mathrm{Mn}^{\mathrm{VI}}$-species. The EELS-imaging of individual elements, ESI-MS, XPS and other techniques established its composition as $\mathrm{Br}\left(\mathrm{Me}_{3} \mathrm{SiO}\right) \mathrm{Mn}^{\mathrm{VI}} \mathrm{O}_{2}$. It revealed significantly improved magnetic moment (SQUID) with isotropic hyperfine splitting of six line spectrum (EPR). The high-oxidation state and incorporated-ligands of the metals present on the active surface of the NPs led to development of a general catalytic process for oxidative heterodifunctionalisation to $\mathrm{C}-\mathrm{C}$ triple bond towards formation of a new $\mathrm{O}-\mathrm{C} / \mathrm{N}-\mathrm{C} / \mathrm{S}-\mathrm{C}$ and $\mathrm{C}-\mathrm{C}$ coupling cum cyclisation to biologically important flavones and their aza- and marcapto-analogues, and valuable enaloxy synthons.

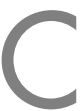
atalysis is like a key to the major chemical processes of industry and academia ${ }^{1-7}$. The mid- and low-valent metal catalysts have been dominating for controlling the reactivity and selectivity of organic transformations $^{1-4}$. Interestingly in the last few years catalysis by high-valent bulk-metals is emerging as an important domain of research ${ }^{5-7}$. We envisioned synthesis of metal- $\mathrm{NPs}^{8-13}$ of higher oxidation state possessing incompletely filled d-shell for unique magnetism, highly active surface, strong electron affinity and redox capability and catalytic site preference for outstanding catalytic activity and selectivity. In particular, ligand-modified version of the high-valent metal-NPs is expected to be a versatile catalyst for the oxidative grafting of C-C triple bond through push-pull mechanism towards heterodifunctionalisation ${ }^{14}$ such as $\mathrm{O}-\mathrm{C} / \mathrm{N}-\mathrm{C} / \mathrm{S}-\mathrm{C}$ and $\mathrm{C}-\mathrm{C}$ coupled fundamental organic transformations cum annulation to flavone analogues. However, controlling size and shape of high-valent metal-NPs is a challenge owing to their less stability at higher temperature and other associated problems. The fabrication of even moderately high-valent metal-NPs $\left(\right.$ e.g. $\left.\mathrm{Mn}^{\mathrm{IV}}\right)$ was usually achieved by thermal decomposition or through stabilization of co-metal ions ${ }^{15,16}$. Thus, we were looking for a straight forward strategy to fabricate nanomaterials of valuable manganese $(\mathrm{VI})^{17,18}$ compounds through reduction of inexpensive $\mathrm{Mn}^{\mathrm{VII}}$ salt (e.g. $\mathrm{KMnO}_{4}$ ) under benign reaction conditions. The designed magnetic $\mathrm{Mn}^{\mathrm{VI}}\left(\mathrm{d}^{1}\right)-\mathrm{NPs}$ bearing ligands such as halogen, oxygen and -OR has several advantages during catalytic cycles. For example, ligands are instrumental during catalysis such as activation of bonds, complexation with the precursors and changing oxidation states of metal to construct desired product and regeneration of the valuable catalyst. Easy separation of the magnetic NPs from the post reaction mixture can be performed by simply using an external magnet and it can be reused further with comparable efficiency ${ }^{19-25}$.

The compounds bearing flavone skeletons are wide spread in Nature and found broad spectrum of applications in medicinal, material and synthetic chemistry ${ }^{26-45}$. For instance, the flavone compounds displayed antiulcer, anticancer, antitumor, antinociceptive, anti-inflammatory, antioxidant, antimicrobial, antiviral, antidiabetic and many other pharmacological properties ${ }^{30-37}$. Tremendous application of flavone compounds has grown interest among the scientists for their synthesis even in $1898^{38}$. Intramolecular cyclization of 2-hydroxychalcones, oxidative cyclization of acetophenone, dehydrative cyclization of 1,3-diaryl diketones, cyclization of alkynones, carbon monoxide insertion of iodophenols with terminal alkynes, cycloaddition of $\alpha$-oxoketene and benzyne, and multistep strategies were developed for their synthesis ${ }^{39-45}$. The aza-(4-quinilinone) $)^{46-48}$ and marcaptoanalogues ${ }^{49,50}$ of flavone are of much interest due to their bioactivity and their syntheses is especially essential for diverse medicinal applications. Thus, a general strategy for direct construction of substituted flavones and their hetero-atomic analogues is desirable for designing new drugs, innovative materials and synthetic compounds. 


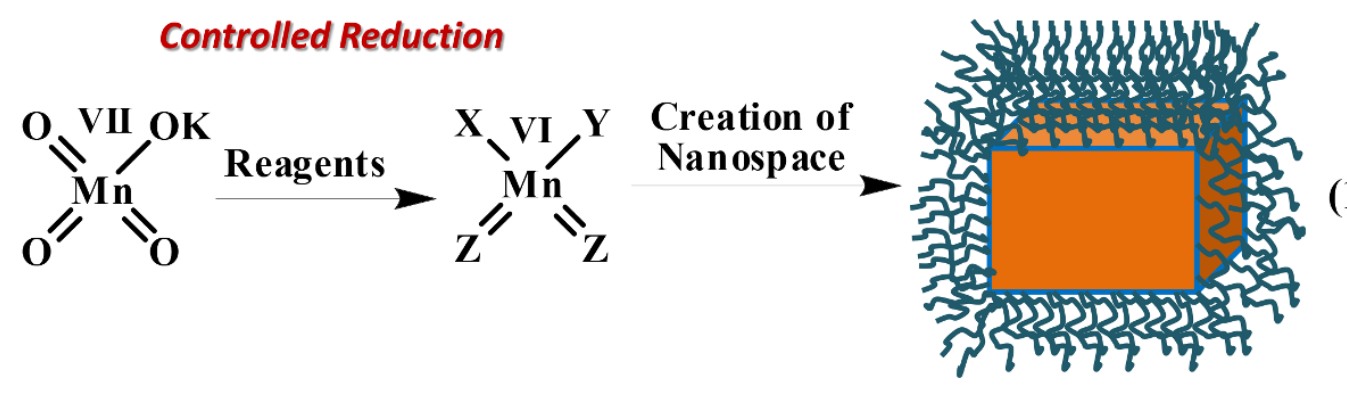

\section{Surfactant Stabilised \\ $\mathrm{Mn}^{\mathrm{VI}}$-NPs}

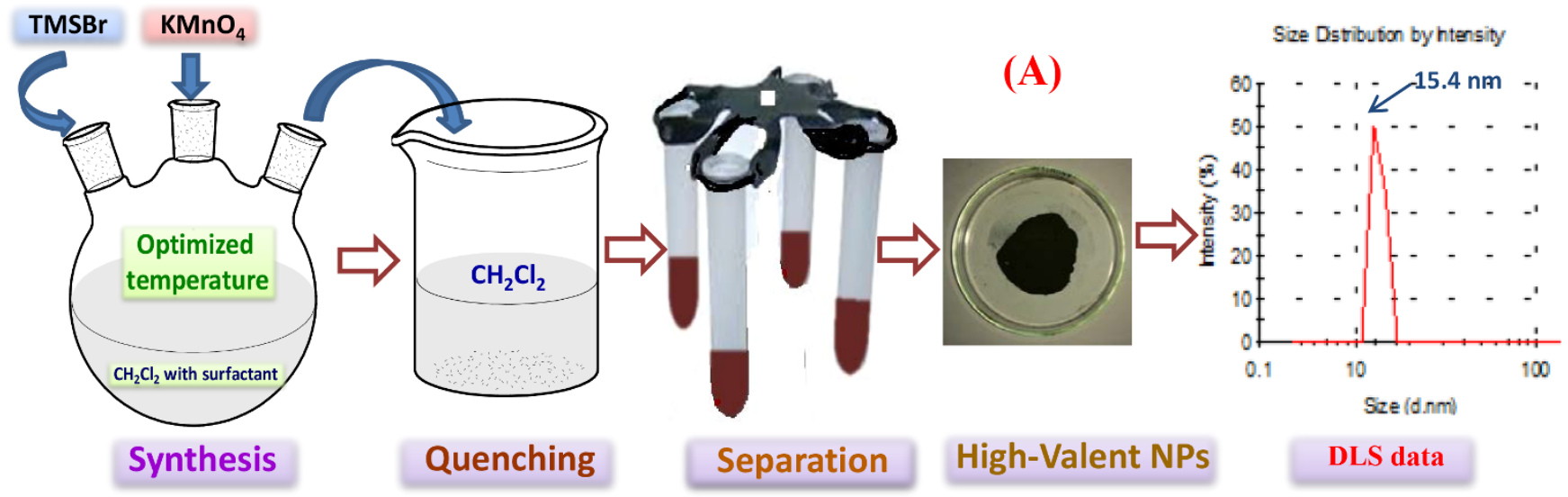

Figure $1 \mid$ Design and synthesis of $\mathrm{Mn}^{\mathrm{VI}}$-NPs.

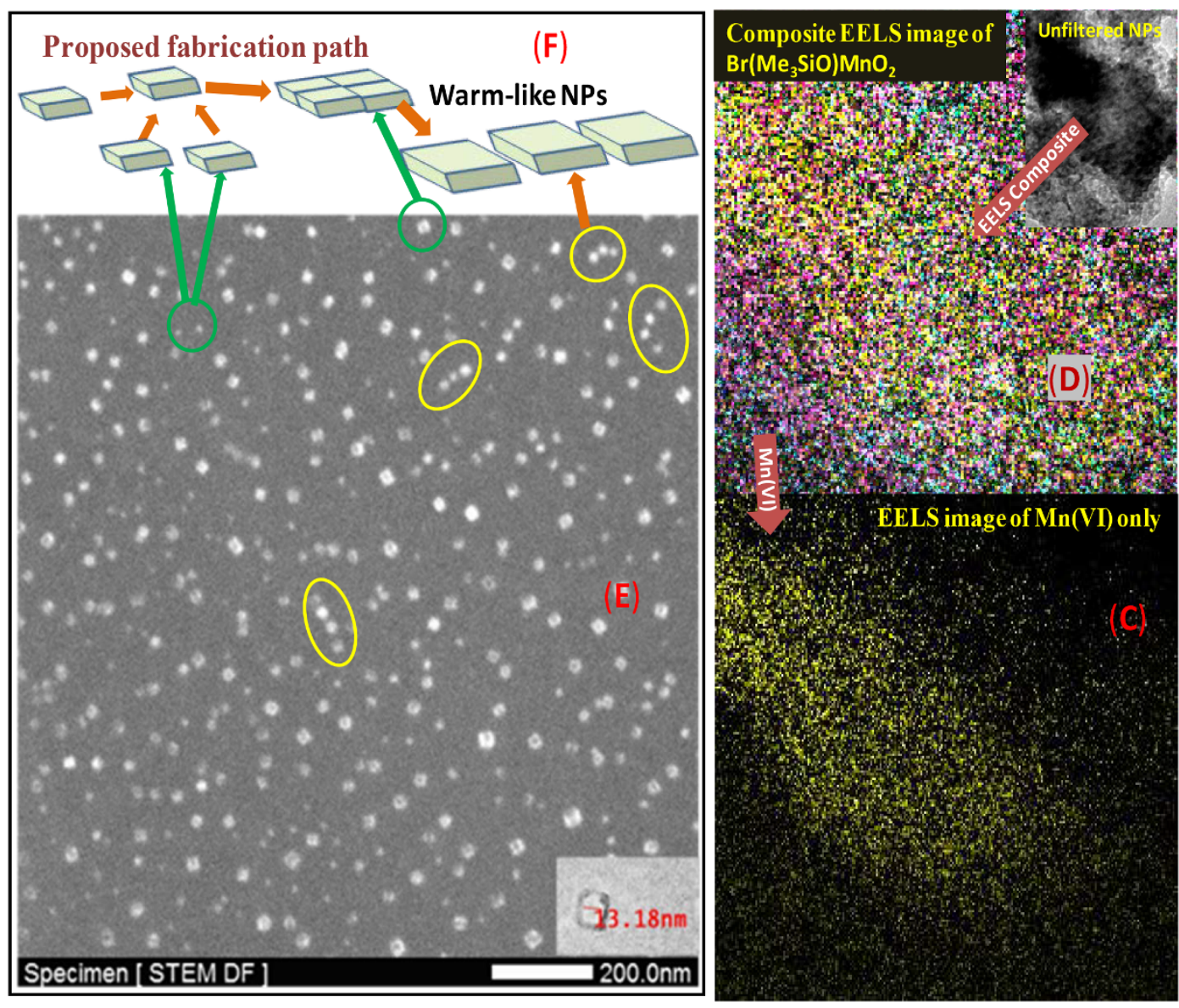

Figure 2 | STEM-imaging, EELS elemental mapping ( $\square / 0 \square / \mathrm{Si} \square / \mathrm{C} \square / \mathrm{H} \square / \mathrm{Br}$ ) and proposed path of fabrication. 

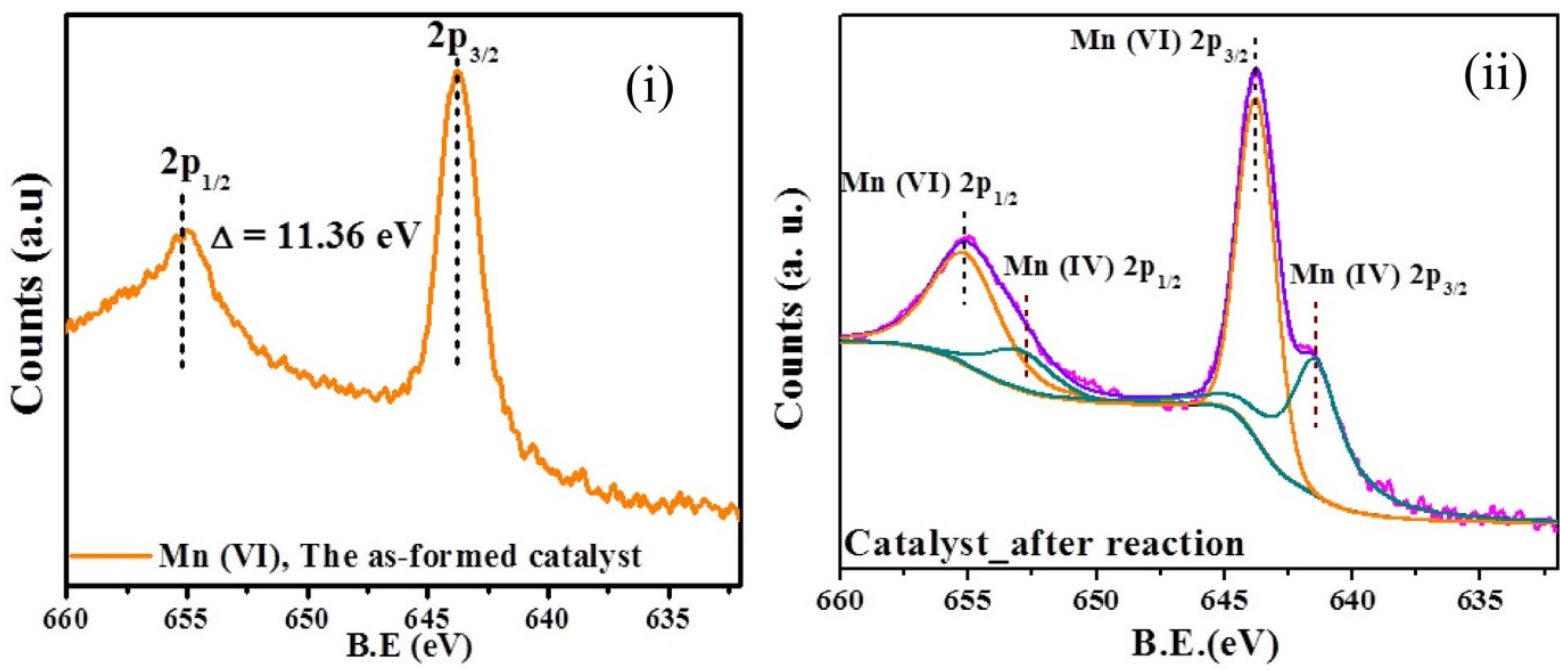

Figure 3 XPS spectra of the fabricated Mn-NPs (i) and recovered NPs from the reaction mixture (ii).

\section{Results}

Design, synthesis and EELS study of the Mn ${ }^{\mathrm{VI}}-\mathrm{NPs}$. The simple $\mathrm{Mn}^{\mathrm{VII}}$ salt $\mathrm{KMnO}_{4}$ was selected as a precursor to design the $\mathrm{XYMn}^{\mathrm{VI}} \mathrm{Z}_{2}$ complex bearing -X, -Y and -Z- groups (eq. 1, Figure 1). We envisioned that the groups such as $-\mathrm{I},-\mathrm{Br},-\mathrm{Cl}$, -OSiMe $\mathrm{OS}_{3},-\mathrm{OTf}$, -O-, -S- etc. possessing good leaving and insertion properties to material will be helpful to accommodate the organic precursors for bond activation around the high-valent metal-sites accomplishing a robust catalysis. After several experiments we found trimethyl silyl bromide as an effective reducing agent to the precursor $\mathrm{KMn}^{\mathrm{VII}} \mathrm{O}_{4}$ towards fabrication of $\mathrm{Mn}^{\mathrm{VI}}$-NPs in $\mathrm{CH}_{2} \mathrm{Cl}_{2}$ containing cetyltrimethyl ammonium bromide (CTAB, $10 \mathrm{~mol} \%)$ at ambient temperature. The NPs were collected from the surfactant-assembled nanospace after one hour of reductive fabrication of the NPs, precipitation of the nanomaterial by addition of $\mathrm{CH}_{2} \mathrm{Cl}_{2}$, collection through centrifuge and successive washing of the brown colour residue (panel A, Figure 1). The dynamic light scattering measurement of the dilute reaction mixture in $\mathrm{CH}_{2} \mathrm{Cl}_{2}$ revealed maximum population of the NPs at $15.4 \mathrm{~nm}$ (panel A, Figure 1). However, the high resolution transmission electron microscope (HR-TEM) imaging of the nanomaterial was inconclusive to determine its morphology. It might be due to rapid damage (panel B, Figure 2) on their organic component-bearing surface by the strong electron-beam of TEM, high reactivity of the metal component of highly oxidation state and/or weak signal generation from the thin nanomaterial. Recently, scanning transmission electron microscope - Electron Energy Loss Spectroscopy (STEMEELS) is emerging as a powerful tool for elemental mapping of nanomaterials ${ }^{51-54}$. Our EELS study for the $\mathrm{Mn}^{\mathrm{VI}}$-NPs revealed presence of worm-like NPs (panel C, Mn only). The mapping of all atoms such as $\mathrm{Mn}, \mathrm{O}, \mathrm{Si}, \mathrm{C}, \mathrm{Br}$ and $\mathrm{H}$ was established by the EELS study. The composite EELS image displayed in panel D and other individual images are supplied in the supporting information. Worm like structure has also been confirmed using AFM study.

To understand the mechanism of fabrication process of the nanomaterials we analyzed a dispersed monolayer material, which was taken out from the ongoing reaction. Gratifyingly it revealed presence of small cube-like NPs along with relatively larger cube-like structure (green circles, panel E) as well as small worm-like structures (yellow circle), which was imaged on dark field (DF) scanning transmission electron microscope. Combination of four small NPs to form the actual unit cell is visible in the panel B with dark-red circle which ultimately construct the worm-like thin NPs. Interestingly the smallest one can couple among four units to form larger cubical nanomaterial which also can arrange nicely between three to four units to form worm-like NPs $(\sim 13 \mathrm{~nm})$. The proposed scheme is presented in the panel F. The reaction mixtures exhibit two UV-vis
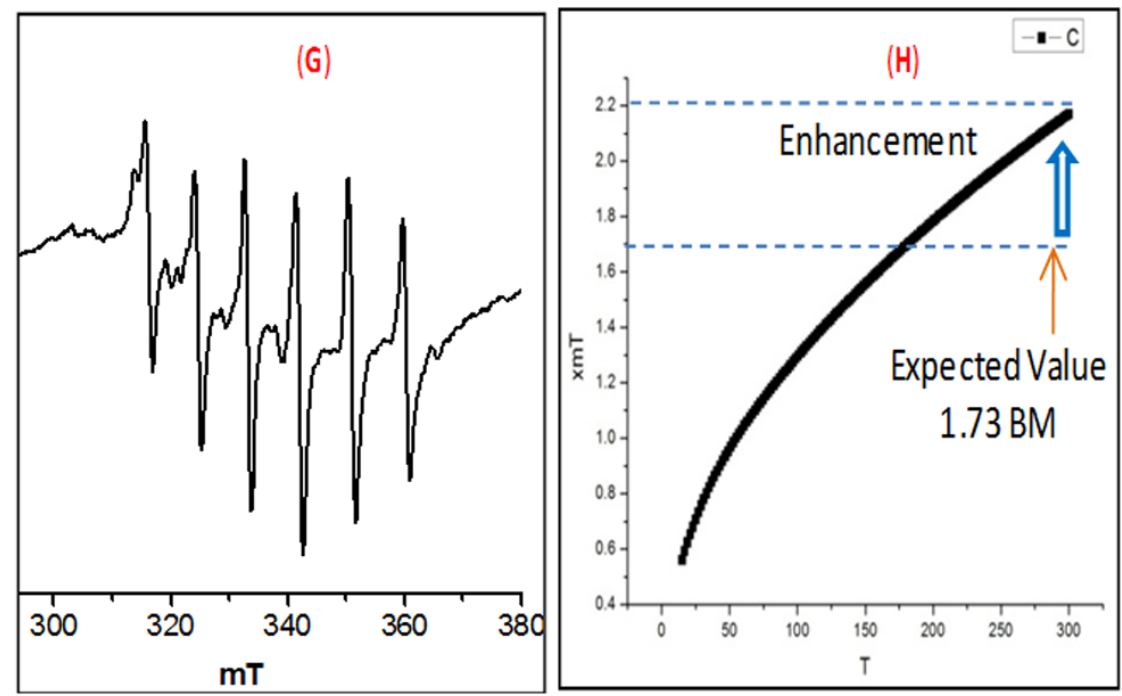

Figure $4 \mid$ EPR and SQUID diagram of the $\mathrm{Mn}^{\mathrm{VI}}$-NPs. 
absorption peaks at 514.1 and $534.9 \mathrm{~nm}$, which also support presence of $\mathrm{Mn}^{\mathrm{VI}}$-NPs of two different size in the reaction mixture.

Elucidation of structure of the $\mathrm{Mn}^{\mathrm{VI}}$-NPs. The orange line in the panel (i), Figure 3 corresponds to the XPS spectrum of the assynthesized Mn-NPs, which indicates presence of manganese in the +6 oxidation state ${ }^{55}$. The pink line in panel (ii), Figure 3 represents the XPS spectrum of the recovered manganese catalyst from the reaction mixture. The deconvolution graph (violet line) was found after fitting the data in XPS software. It showed presence of a mixture of $\mathrm{Mn}^{\mathrm{VI}}$ and $\mathrm{Mn}^{\mathrm{IV}}$ in the recovered material, which matches with the standard curve for $\mathrm{Mn}^{\mathrm{VI}}$ (orange line) and $\mathrm{Mn}^{\mathrm{IV}}$ (green line). The powder X-ray diffraction peaks $(2 \theta)$ of the solid Mn-NPs appeared at $28.1^{\circ}, 40.2^{\circ}, 49.8^{\circ}, 58.1^{\circ}, 66.1^{\circ}$ and $73.1^{\circ}$. Electronspray ionizationmass spectrometry (ESI-MS) of the NPs is performed in $\mathrm{CH}_{3} \mathrm{CN}$ medium and the appearance of ESI-MS-generated peak at 254.8885 dalton established the composition $\mathrm{Mn}^{\mathrm{VI}}$-NPs as $\mathrm{Br}\left(\mathrm{Me}_{3} \mathrm{SiO}\right) \mathrm{MnO}_{2}$. Presence of $\left(\mathrm{CH}_{3}\right)_{3} \mathrm{SiOMn}$ group was verified by measurement of FTIR spectroscopy of the nanomaterial, which revealed appearance of FTIR stretching vibration for C-H at $2922 \mathrm{~cm}^{-1}$, Si-O at $1393 \mathrm{~cm}^{-1}$ and $\mathrm{Mn}^{\mathrm{VI}}-\mathrm{O}$ broad peaks around $511 \mathrm{~cm}^{-1}$. The peak at $\delta 1.46$ in the solid state ${ }^{1} \mathrm{H}-\mathrm{NMR}$ confirmed the presence of methyl group of $-\mathrm{OSi}\left(\mathrm{CH}_{3}\right)_{3}$ in the functionalized NPs. All other spectra are available in the supporting information.

Unusual nanoscale magnetism of the high-valen $\mathrm{Mn}^{\mathrm{VI}}$-NPs. Interestingly, spin only magnetic moment of $\mathrm{Mn}^{\mathrm{VI}}$-complex in nano-state is found to be $2.2 \mathrm{BM}$ at room temperature, which is unusually high relative to the expected value $(\sim 1.73 \mathrm{BM})$ of bulk- $\mathrm{Mn}^{\mathrm{VI}}$ compound bearing $3 \mathrm{~d}^{1}$ electron. The X-band EPR spectrum (panel G, Figure 4) of the powdered nanomaterial at $-78^{\circ} \mathrm{C}$ (liquid $\mathrm{N}_{2}$ ) showed a significantly improved isotropic hyperfine splitting ${ }^{55}(\mathrm{Mn} ; I=5 / 2)$ of six line spectrum $(\mathrm{g}=1.99836)$. Earlier, Wieghardt et al. reported a six line EPR spectrum $(\mathrm{g} \sim 2.0)$ of $\left[(\text { cyclam }) \mathrm{Mn}^{\mathrm{VI}}(\mathrm{N})\left(\mathrm{NCCH}_{3}\right)\right]^{3+}$-complex ${ }^{56}$. The higher value of magnetic moment of the small nanomaterial and hyperfine splitting in EPR spectrum may be attributed due to their exceptionally high oxidation state and existence of magnetic vector in an unidirectional ${ }^{56}$ fashion. It led us to execute the temperaturedependent SQUID measurement ${ }^{57}$ of the nanomaterial, which also revealed (panel $\mathrm{H}$ ) higher magnetic moment $(2.2 \mathrm{BM})$. It clearly indicates the special arrangement (F, Figure 1$)$ of the tiny high- valent magnetic NPs (vector) which eventually added the vector towards significant enhancement of the magnetic moment.

Discovery of C-X/C-C coupled annulation catalysis. Design, synthesis and development of new catalytic activity of a material are of intense interest to the chemical science community because the catalyst offers novel reactivity and selectivity towards synthesis of valuable compounds. An annulation reaction that can selectively execute $\mathrm{O}-\mathrm{C} / \mathrm{C}-\mathrm{C}$ coupling through grafting of $\mathrm{C}-\mathrm{C}$ triple bond is a very promising strategy towards direct construction of functionalised analogues of natural product flavones (6, eq. 2, Figure 5). Herein, we for the first time synthesize $\mathrm{Mn}^{\mathrm{VI}}$-NPs, developed outstanding catalytic activity for $\mathrm{O}-\mathrm{C} / \mathrm{N}-\mathrm{C} / \mathrm{S}-\mathrm{C}^{20,25}$ and $\mathrm{C}-\mathrm{C}$ coupled annulation to flavone skeletons (6-8) and enaloxy synthons (9), easy recovery of the magnetic catalyst from the post reaction mixture by using external magnet and successfully recycled, and several facets of catalysis for $\mathrm{C}-\mathrm{C}$ triple bond functionalisation reactions. We first observed the oxidative coupling between functionalized salicylaldehyde derivative (1a, entry 1 ) and a deactivated alkyne (2a) to undergo annulation reaction at ambient temperature in THF towards direct construction of valuable flavones $(6 \mathrm{a}, 20 \%$ yield) in presence of catalytic amount (10 mol\%) of the $\mathrm{Mn}^{\mathrm{VI}}-\mathrm{NPs}, \mathrm{NaIO}_{4}(1.1 \mathrm{mmol})$ and triethylamine. Gratifyingly the reaction was complete in $4 \mathrm{~h}$ and yield (80\%) as well as catalyst loading $(10 \mathrm{~mol} \%)$ were improved by rising the reaction temperature to $70^{\circ} \mathrm{C}$. $\mathrm{NaIO}_{4}$ was needed as a stoichiometric oxidant for the $\mathrm{O}-\mathrm{C}$ and $\mathrm{C}-\mathrm{C}$ coupled annulation process because the yield

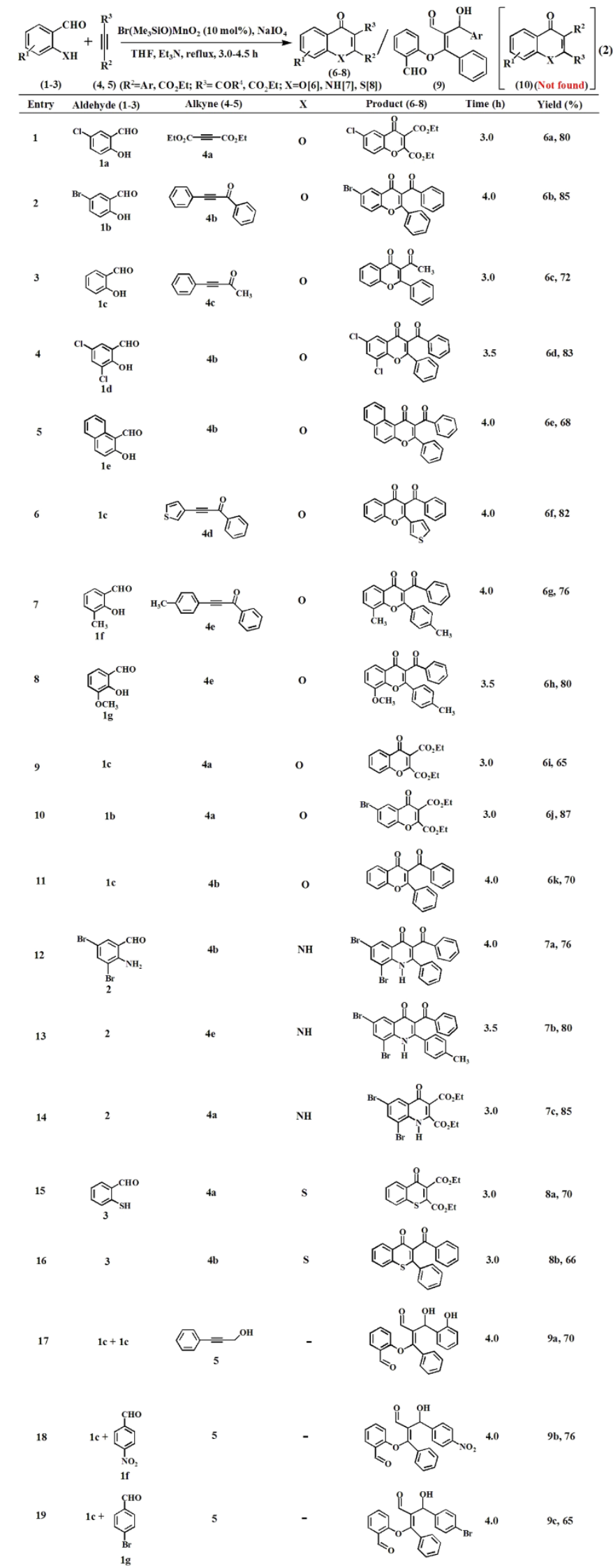

Figure $5 \mid$ Direct construction of flavone analogues and 3-oxyenals. 

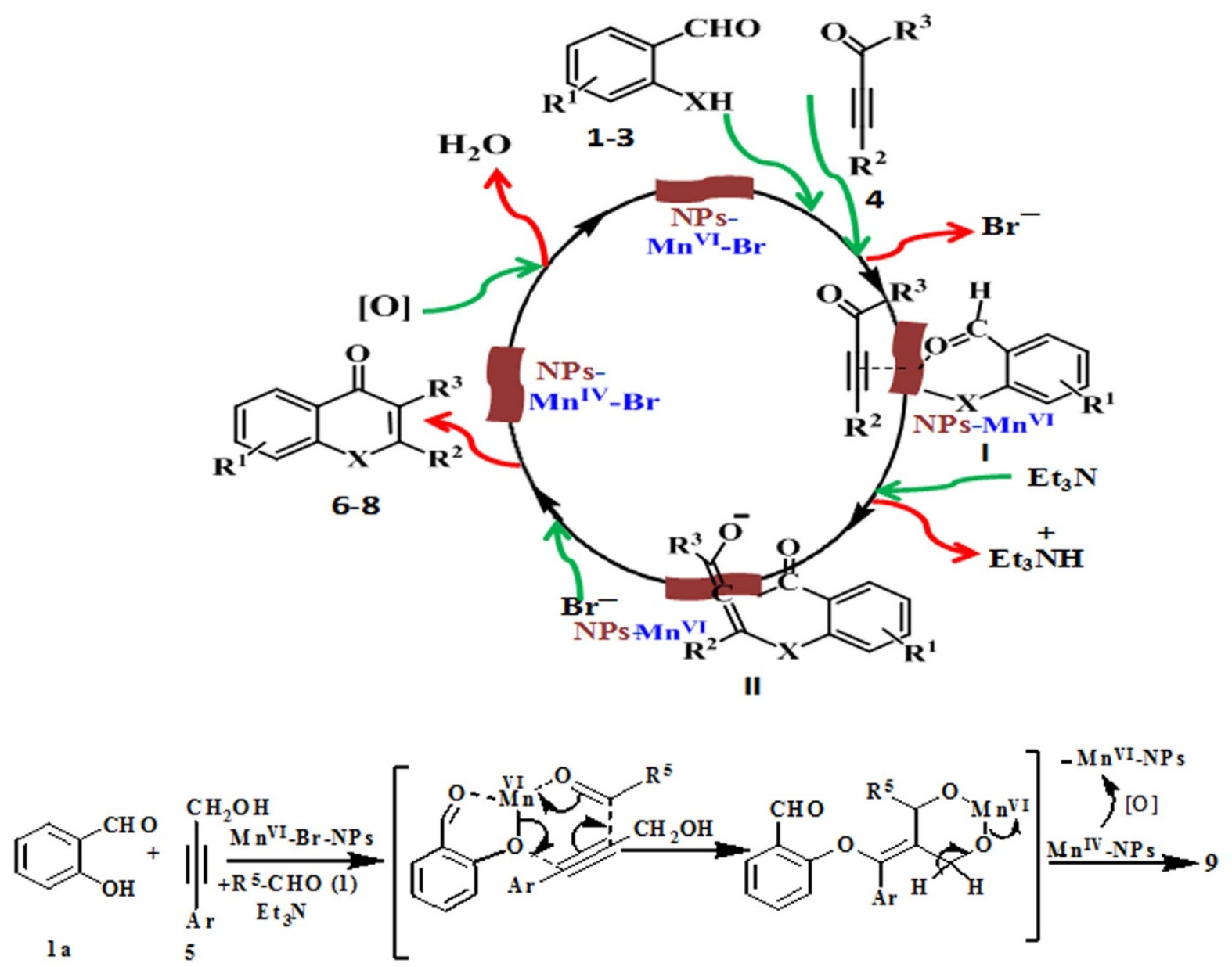

Reaction condition: $\mathrm{BrMe}_{3} \mathrm{SiOMnO}_{2}(10 \mathrm{~mol} \%), \mathrm{NaIO}_{4}(1.1 \mathrm{~m} \mathrm{~mol}), \mathrm{THF}, \mathrm{Et}_{3} \mathrm{~N}$, r ef lux

Figure 6 | Possible annulation catalytic cycle for flavones and enaloxy synthons.

was drastically reduced (7\%) in its absence under the optimized conditions. On carrying out the reaction using bulk- $\mathrm{Mn}^{\mathrm{VI}}$ compound as a catalyst conversion of the starting material was very poor $(\sim 40 \%$ conversion) even after prolong heating $(\sim 24 \mathrm{~h})$. Similarly, the product 6a was not found in absence of the catalyst. It indicates that surface of the functionalized $\mathrm{Mn}^{\mathrm{VI}}$-NPs is highly active towards binding the precursors (1a and 4a) which led to grafting of the triple bond with rapid annulation. This catalytic strategy was helpful for synthesis of a large number of flavones (6a-k, entries $1-11$ ) within 3-4 h by varying the starting ingredients. Methyl, halogen, methoxy etc. substituted aromatic rings, heterocycles, carbonyl, ester functionalities were tolerated under the above optimized reaction conditions. The feasibility of the reaction was also checked with highly deactivated alkyne such as diethyl acetylene dicarboxylate, which produced the desired flavones $(\mathbf{6} \mathbf{a}, \mathbf{6 i}$ and $\mathbf{6 j})$. Interestingly, the functionalized surfaces of high-valent-NPs are very much site-selective for binding the precursors which led to complete regioselective annulation to compound 6. The other possible regioisomer 10 (eq. 2) was not found using unsymmetrical alkynes (entries 2-8). The nitrogen analogues of flavones i.e. 4-quinolinones (7a-c, entries 12-14) and marcaptoflavones (8a,b, entries 15-16) were also been synthesized using 2aminobenzaldehyde and 2-marcaptobenzaldehyde respectively under the similar reaction conditions. Thus, the newly synthesized highvalent $\mathrm{Mn}^{\mathrm{VI}}$-NPs were found as robust catalyst for developing a rapid and general strategy to bioactive flavone analogues with outstanding regioselectivity and high yield. Surprisingly on replacement of carbonyl group by alcoholic - $\mathrm{OH}$ in the triple bond the $\mathrm{C}-\mathrm{C}$ coupled annulation was completely unsuccessful to afford corresponding flavone (6, entry 17). In turn, it underwent C-C coupling with another aldehyde functionality to afford highly functionalised valuable enaloxy synthons (9a-c, entries 17-19) in 4 h with $65-76 \%$ yield.

The possible role of the high-valent $\mathrm{Mn}^{\mathrm{VI}}$-NPs in the robust catalysis. Exact mechanism of the catalytic process is unknown to us. However, high oxidation state of the $\mathrm{Mn}^{\mathrm{VI}}$-NPs, catalytic site-preference, metalbearing good leaving groups, and highly active nanoscale-surface with strong electro affinity of the NPs lead to activation of the precursor aldehyde (1-3) and alkyne (4) through formation of an assembly (I, eq. 3, Figure 6) involving $\mathrm{C}-\mathrm{C}$ triple bond, carbonyl oxygen and $-\mathrm{XH}$. In this step bromide was lost from the NPs and Mn-X bond was formed. The reactive intermediated II is expected to form by deprotonation of aldehyde through - $\mathrm{CO}-H$ activation and regioselective nucleophilic addition of $-\mathrm{X}$ from $\mathrm{C}_{3}$ of the alkyne (4) to generate $\mathrm{O}-\mathrm{C} / \mathrm{N}-\mathrm{C} / \mathrm{S}-\mathrm{C}$ bond. During optimization of the reaction we observed that presence of base $\mathrm{NEt}_{3}$ was essential in the catalysis process, which might be needed to abstract aldehyde-sp ${ }^{2} \mathrm{C}-H$ for transforming I to II. The desired product 6,7 or 8 was produced via oxidative $\mathrm{C}-\mathrm{C}$ coupling of the allene-like intermediate(II) with insertion of bromide and release of reduced $\mathrm{Mn}^{\mathrm{IV}}$-modified NPs. Trace amount of $\mathrm{Mn}^{\mathrm{IV}}$ along with $\mathrm{Mn}^{\mathrm{VI}}$ was detected via XPS analysis of the recovered catalyst from the ongoing reaction mixture. (SI) Catalytic cycle is maintained through regeneration of the $\mathrm{Mn}^{\mathrm{VI}}-\mathrm{NPs}$ at the surface by the stoichiometric oxidant sodium metaperiodate $\left(\mathrm{NaIO}_{4}\right)$ under the reaction conditions. To understand whether the involvement of carbonyl oxygen of the alkyne with the high-valent $\mathrm{Mn}^{\mathrm{VI}}-\mathrm{NPs}$ is essential for the oxidative $\mathrm{C}-\mathrm{C}$ coupled annulation process we used its reduced form i.e. propargyl alcohol (5) under the similar reaction conditions. However, corresponding oxidative C-C coupled annula- 
(6)

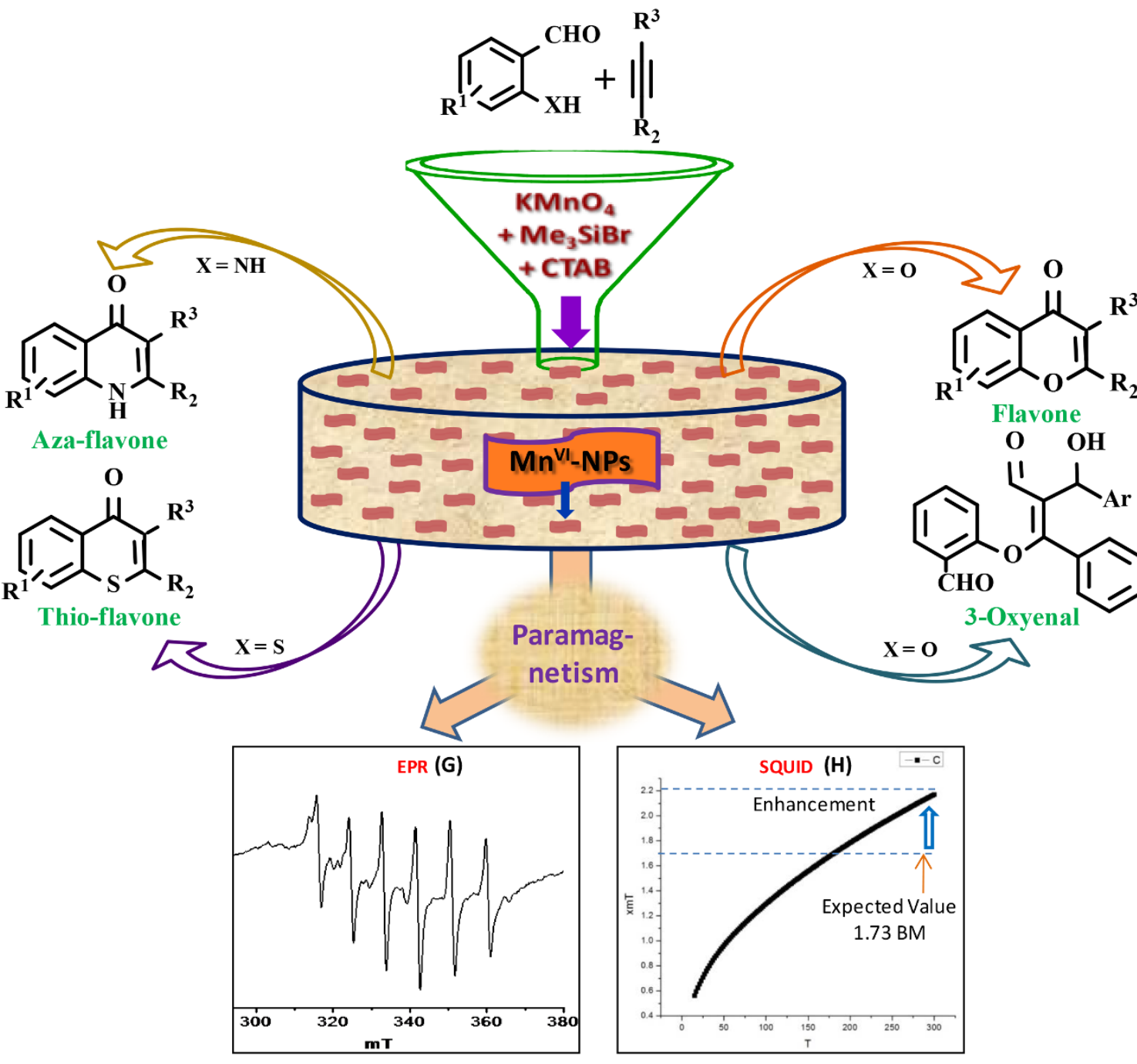

Figure $7 \mid$ High-valent $\mathrm{Mn}^{\mathrm{VI}}$-NPs and its innovative properties.

tion product (6, Figure 5) involving aldehyde group of salicylaldehyde (1) was not found from the post reaction mixture. It supports our proposed reaction pathway, which passes through initial coordination of the carbonyl oxygen of 4 (I) with $\mathrm{Mn}^{\mathrm{VI}}$-NPs. Interestingly the highvalent-NPs completely changed the $\mathrm{O}-\mathrm{C} / \mathrm{C}-\mathrm{C}$ coupling reaction path and it was joined to another molecule of salicylaldehyde with simultaneous oxidation of $-\mathrm{CH}_{2} \mathrm{OH}$ of 5 to aldehyde affording highly functionalized synthon 9a (entry 17, Figure 5). The catalytic three component coupling process was also successfully carried out in presence of other aldehydes (9b,c, entries 18,19). It indicates that oxidation took place after the $\mathrm{Mn}^{\mathrm{VI}}$-NPs catalyzed cascade type of O-C and C$\mathrm{C}$ coupling, which is expected to proceed through formation of two successive six member transition states III and IV (eq. 4, Figure 6). XPS studies (Figure 3) showed that recovered catalyst was the mixture of $\mathrm{Mn}^{\mathrm{IV}}$ and $\mathrm{Mn}^{\mathrm{VI}}$, which were very difficult to separate for characterization. It supports our proposed reaction pathway, which passes through transformation of intermediate II to desired product (6-8) with generation of $\mathrm{Mn}^{\mathrm{IV}}$-species (Figure 6). Interestingly we observed in our experiments using the recovered catalyst that it was equally efficient to as-fabricated Mn-NPs in presence of $\mathrm{NaIO}_{4}$ due to transformation of $\mathrm{Mn}^{\mathrm{IV}}$ to $\mathrm{Mn}^{\mathrm{VI}}$ under the reaction conditions.

\section{Discussion}

In this article, we have demonstrated an innovative design and fabrication of a functionalised high-valent nanomaterial through formation of a new $\mathrm{Mn}^{\mathrm{VI}}$-compound under benign reaction conditions.
Herein, we report an unprecedented reductive transformation of readily available $\mathrm{Mn}^{\mathrm{VII}}$-salt $\mathrm{KMnO}_{4}$ to valuable $\mathrm{Mn}^{\mathrm{VI}}$-species using $\mathrm{Me}_{3} \mathrm{SiBr}$ as a mild reducing agent. The $\mathrm{Mn}^{\mathrm{VI}}$-NPs bearing uncommon six oxidation state, exchangeable ligands, catalytic-site preference possibility, strong electron affinity, unique redox and magnetic property is the potential candidate for unique magnetism, material and catalysis. However, fabrication of well defined high-valent metal-NPs is a difficult job because of its higher oxidation state, reactivity and less stability under the heating conditions which is usually required during synthesis of a nanomaterial. Herein, a benign strategy is devised for fabrication of the high-valent metal-NPs of uniform size and shape through in situ generation of the ingredient and creation of nanospace utilizing inexpensive $\mathrm{KMnO}_{4}, \mathrm{Me}_{3} \mathrm{SiBr}$ and $\mathrm{CTAB}$ (Figure 7). The modern EELS imaging technique is used for mapping of individual elements present in the nanomaterial and it revealed formation of worm-like structure. The possible mechanism of unidirectional packing of the nanomaterial is also predicted (panel F, Figure 2) with the experimental evidence. The primary formula of the NPs was established as $\mathrm{Br}\left(\mathrm{Me}_{3} \mathrm{SiO}\right) \mathrm{Mn}^{\mathrm{VI}} \mathrm{O}_{2}$. A significantly improved magnetic property was observed in the X-band ESR spectroscopy of the NPs with isotropic hyperfine splitting of six line spectrum (panel G, Figure 7). It also showed higher magnetic moment with respect to common $\mathrm{Mn}^{\mathrm{VI}}$-compounds $\left(\mathrm{d}^{\mathrm{l}}\right)$, which is comparable to the temperature dependant SQUID data (panel H). As expected the high-oxidation state and incorporated-ligands of the metals present on the active surface of the NPs was crucial to develop a robust catalytic process for 
oxidative heterodifunctionalisation of $\mathrm{C}-\mathrm{C}$ triple bond towards formation of a new $\mathrm{O}-\mathrm{C} / \mathrm{C}-\mathrm{C}$ coupling cum cyclisation to afford a wide range of biologically important flavone (6a-k, eq. 5, Figure 7) compounds. Herein, we have introduced a general strategy for direct construction of the bioactive flavone with outstanding regioselectivity and its analogues such as azaflavones (7a-c, eq. 6) and marcaptoflavones (8a,b, eq. 7), and a valuable 3 -oxyenal synthon (9a-c, eq. 8) involving and $\mathrm{N}$ $\mathrm{C} / \mathrm{S}-\mathrm{C} / \mathrm{O}-\mathrm{C}$ and $\mathrm{C}-\mathrm{C}$ coupling, which is quite important to synthetic and medicinal chemistry - the most active area of contemporary research. We believe that the intriguing and inspiring strategy for fabrication of the functionalized high-valent metal-NPs, its unique magnetic property and diverse catalytic activity will open up a new avenue in science and technology.

\section{Methods}

Synthesis of $\mathrm{Mn}^{\mathrm{VI}}$-NPs. In a $100 \mathrm{~mL}$ round bottomed flask, CTAB (364 mg, $1 \mathrm{mmol})$ and $\mathrm{CH}_{2} \mathrm{Cl}_{2}(36.4 \mathrm{~mL})$ were taken together and stirred magnetically for $5 \mathrm{~min} . \mathrm{KMnO}_{4}(158 \mathrm{mg}, 1 \mathrm{mmol})$ was added into the solution and stirring was continued. $\mathrm{Me}_{3} \mathrm{SiBr}(306 \mathrm{mg}, 2 \mathrm{mmol})$ was added drop wise at $0^{\circ} \mathrm{C}$ and content of the reaction mixture was stirred for $45 \mathrm{~min}$. Finally the reaction mixture was poured into $200 \mathrm{~mL}$ of $\mathrm{CH}_{2} \mathrm{Cl}_{2}$ and centrifuged, washed with $\mathrm{CH}_{2} \mathrm{Cl}_{2}(5 \times 20 \mathrm{~mL})$ and dried under reduced pressure at ambient temperature to afford $\mathrm{Mn}^{\mathrm{VI}}-\mathrm{NPs}$ as a brown solid material (yield: $52 \%$; $138 \mathrm{mg}, 0.52 \mathrm{mmol}$ ). The characterization data of the new nanomaterial such as FTIR, NMR, ESI-MS, powder XRD, UV-vis, AFM, FESEMEDS for elements, EELS elemental mapping and the important spectra are incorporated in the supporting information.

Synthesis of flavones. To a solution of salicylaldehyde or 2-amino-3,5-dibromobenzaldehyde or thio-salicylaldehyde $(1.0 \mathrm{mmol})$ in THF $(20 \mathrm{~mL})$ triethylamine $(1.1 \mathrm{mmol}, 111 \mathrm{mg}$ ) was added drop wise under stirring condition. The propargyl ketone $(1.0 \mathrm{mmol})$ was added to it. The $\mathrm{Mn}^{\mathrm{VI}}$-NPs $(10 \mathrm{~mol} \%)$ and sodium periodate $(1.1 \mathrm{mmol}, 235 \mathrm{mg})$ were added and allowed to reflux at $70^{\circ} \mathrm{C}$ for $3-4 \mathrm{~h}$. The reaction was monitored by thin layer chromatography (TLC). The solvent of the post reaction mixture was removed under reduced pressure at room temperature and extracted with EtOAc $(2 \times 20 \mathrm{~mL})$. The combined organic layer was washed successively with saturated sodium bicarbonate solution $(1 \times 10 \mathrm{~mL})$ and brine $(3 \times 10 \mathrm{~mL})$. It was dried over anhydrous $\mathrm{Na}_{2} \mathrm{SO}_{4}$, filtered and evaporated to dryness in a rotary evaporator under reduced pressure at room temperature. Thus, the reaction with 5chlorosalicylaldehyde $(1.0 \mathrm{mmol}, 156 \mathrm{mg})$ and diethylacetylenedicarboxylate $(1.0 \mathrm{mmol}, 170 \mathrm{mg}$ ) afforded 6-chloro-4-oxo- $4 H$-chromene-2,3-dicarboxylic acid diethyl ester (6a) which was isolated after purification by column chromatography on silica gel (60-120 mesh) using ethyl acetate-petroleum ether $(1: 9, \mathrm{v} / \mathrm{v})$ as an eluent to afford $80 \%$ (259 $\mathrm{mg}, 0.70 \mathrm{mmol}$ ) yield. The synthesized flavones derivatives $(6 \mathbf{a}-\mathbf{k})$, azaflavones $(7 \mathbf{a}-\mathrm{c})$ and marcaptoflavones $(8 \mathrm{a}, \mathrm{b})$ were characterised by recording NMR $\left({ }^{13} \mathrm{H}\right.$ and $\left.{ }^{13} \mathrm{C}\right)$, FTIR and Mass (HR-MS) spectra. The characterization data of the all new compounds and their spectra are reported in the supporting information.

1. Rothenberg, G. Catalysis: concepts and green applications. (Wiley-VCH Verlag $\mathrm{GmbH} \&$ Co. KGaA, Weinheim, 2008).

2. Peplow, M. Catalysis: the accelerator. Nature 495, S10-S11 (2013).

3. Ghosh, S., Khamarui, S., Gayen, K. S. \& Maiti, D. K. ArCH(OMe $)_{2}-\mathrm{PAt}^{\mathrm{IV}}$-catalyst originator for diverse annulation catalysis. Sci. Rep. 3, 2987 (2013).

4. Jørgensen, K. A. Catalytic asymmetric hetero-diels-alder reactions of carbonyl compounds and imines. Angew. Chem. Int. Ed. 39, 3558-3588 (2000).

5. Li, Z., Assary, R. S., Atesin, A. C., Curtiss, L. A. \& Marks, T. J. Rapid ether and alcohol C-O bond hydrogenolysis catalyzed by tandem high-valent metal triflate + supported Pd catalysts. J. Am. Chem. Soc. 136, 104-107 (2014).

6. Bart, S. C., Anthon, C., Heinemann, F. W., Bill, E., Edelstein, N. M. \& Meyer, K. Carbon dioxide activation with sterically pressured mid- and high-valent uranium complexes. J. Am. Chem. Soc. 130, 12536-12546 (2008).

7. Jr, L. Q. \& Tolman, W. B. Biologically inspired oxidation catalysis. Nature 455, 333-340 (2008).

8. Turner, M. et al. Selective oxidation with dioxygen by gold nanoparticle catalysts derived from 55-atom clusters. Nature 454, 981-984 (2008).

9. Jiang, Q. \& Lu, H. M. Size dependent interface energy and its applications. Surf. Sc. Rep. 63, 427-464 (2008).

10. Sau, T. K., Rogach, A. L., Jäckel, F., Klar, T. A. \& Feldmann, J. Properties and applications of colloidal nonspherical noble metal nanoparticles. Adv. Mater. 22, 1805-1825 (2010).

11. Gayen, K. S. et al. A. Cu(0) nanoparticle catalyzed efficient reductive cleavage of isoxazoline, carbonyl azide and domino cyclization in water medium. Green Chem. 14, 1589-1592 (2012).

12. Singhal, A., Morris, V. B., Labhasetwar, V. \& Ghorpade, A. Nanoparticlemediated catalase delivery protects human neurons from oxidative stress. Cell Death Disease 4, 903 (2013).
13. Ranu, B. C., Saha, D., Kundu, D. \& Mukherjee, N. inNanocatalysis: Synthesis and Applications of Aryl carbon-heteroatom coupling reactions using nano-metal catalyst (eds. Polshettiwar, V.\& Asefa, T. Wiley-VCH, 2013).

14. Pandit, P., Gayen, K. S., Khamarui, S., Chatterjee, N. \& Maiti, D. K. Addition of halide to $\pi$-bond directly from aqueous $\mathrm{NaX}$ solution: a general strategy for installation of two different functional groups. Chem. Commun. 47, 6933-6935 (2011).

15. Ahmad, T., Ramanujachary, K. V., Lofland, S. E. \& Ganguli, A. K. Nanorods of manganese oxalate: a single source precursor to different manganese oxidenanoparticles ( $\left.\mathrm{MnO}, \mathrm{Mn}_{2} \mathrm{O}_{3}, \mathrm{Mn}_{3} \mathrm{O}_{4}\right)$. J. Mater. Chem. 14, 3406-3410 (2004).

16. Menaka, S. et al. Stabilization of Mn(IV) in nanostructured zinc manganese oxide and their facile transformation from nanospheres to nanorods. J. Mater. Chem. 21, 8566-8573 (2011).

17. Nagashima, K., Mitsudome, T., Mizugaki, T., Jitsukawa, K. \& Kaneda, K. Creation of a high-valent manganese species on hydrotalcite and its application to the catalytic aerobic oxidation of alcohols. Green Chem. 12, 2142-2144 (2010).

18. McCleverty, J. A. \& Meyer, T. J. Comprehensive coordination chemistry II: transition metal group 7 and 8 (Vol. 5, Elsevier Pergamon, Oxford, UK, 2005).

19. Polshettiwar, V. et al. Magnetically recoverable nanocatalysts. Chem. Rev. 111, 3036-3075 (2011).

20. Baig, R. B. N. \& Varma, R. S. A highly active and magnetically retrievable nanoferrite-DOPA-copper catalyst for the coupling of thiophenols with aryl halides. Chem. Commun. 48, 2582-2584 (2012).

21. Baig, R. B. N. \& Varma, R. S. Organic synthesis via magnetic attraction: benign and sustainable protocols using magnetic nanoferrites. Green Chem. 15, 398-417 (2013).

22. Gawande, M. B., Brancoa, P. S. \& Varma, R. S. Nano-magnetite $\left(\mathrm{Fe}_{3} \mathrm{O}_{4}\right)$ as a support for recyclable catalysts in the development of sustainable methodologies. Chem. Soc. Rev. 42, 3371-3393 (2013).

23. Baig, R. B. N. \& Varma, R. S. Magnetically retrievable catalysts for organic synthesis. Chem. Commun. 49, 752-770 (2013).

24. Gawande, M. B., Luque, R. \& Zboril, R. The rise of magnetically recyclable nanocatalysts. ChemCatChem. 6, 3312-3313 (2014).

25. Baig, R. B. N., Nadagouda, M. N. \& Varma, R. S. Carbon-coated magnetic palladium: applications in partial oxidation of alcohols and coupling reactions. Green Chem. 16, 4333-4338 (2014).

26. Andersen, M. \& Markham, K. R. Flavonoids: chemistry, biochemistry and applications.(CRC Press, Tailor \& Francis Group, Boca Raton, 2006).

27. Ermeydan, M. A., Cabane, E., Masic, A., Koetz, J. \& Burgert, I. Flavonoid insertion into cell walls improves wood properties. ACS Appl. Mater. Interfaces 4, 5782-5789 (2012).

28. Fletcher, J. N. et al. In vitro evaluation of flavonoids from eriodictyon californicum for antagonist activity against the bitterness receptor hTAS2R31. J. Agric. Food Chem. 59, 13117-13121 (2011).

29. Jeong, E. H. et al. Efficient delivery of siRNAs by a photothermal approach using plant flavonoid-inspired gold nanoshells. Chem. Commun. 50, 13388-13390 (2014).

30. Zou, J.-H., Yang, J. S. \& Zhou, L. Acylated flavone C-glycosides from Trollius ledebouri. J. Nat. Prod. 67, 664-667 (2004).

31. Rao, J. M., Muralidhar, G. P., Satyanarayan, N. D., Srinivas, P. V. \& Yadav, J. S. Protective effect of flavone derivatives on ulcers in different gastric ulcer inducing models. Patent-504, India [533/DEL/08](2008).

32. Borghi, S. M. et al. Vitexin inhibits inflammatory pain in mice by targeting TRPV1, oxidative stress, and cytokines. J. Nat. Prod. 76, 1141-1149 (2013).

33. Wei, Y. et al. Revolving door action of breast cancer resistance protein (BCRP) facilitates or controls the efflux of flavone glucuronides from UGT1A9overexpressing HeLa cells. Mol. Pharmaceutics 10, 1736-1750 (2013).

34. Polier, G. et al. Wogonin and related natural flavones are inhibitors of CDK9 that induce apoptosis in cancer cells by transcriptional suppression of Mcl-1. Cell Death and Disease 2, 182 (2011).

35. Narwal, M., Haikarainen, T., Fallarero, A., Vuorela, P. M. \& Lehtiö, L. Screening and structural analysis of flavones inhibiting tankyrases. J. Med. Chem. 56, 3507-3517 (2013).

36. Verma, A. K. et al. Flavone-based novel antidiabetic and antidyslipidemic agents. J. Med. Chem. 55, 4551-4567 (2012).

37. Gobbi, S. et al. Lead optimization providing a series of flavone derivatives as potent nonsteroidal inhibitors of the cytochrome $\mathrm{P} 450$ aromatase enzyme. J. Med. Chem. 49, 4777-4780 (2006).

38. Emilewicz, T. \& Kostanecki, St. v. Synthese des 3-oxyflavons. Chem. Ber. 31, 696-705 (1898).

39. Shah, D. N., Parikh, S. K. \& Shah, N. M. Synthesis of flavone- and flavonol-6 carboxylic acid and related derivatives. J. Am. Chem. Soc. 77, 2223-2224 (1955).

40. Seijas, J. A., Vázquez-Tato, M. P. \& Carballido-Reboredo, R. Solvent-free synthesis of functionalized flavones under microwave irradiation. J. Org. Chem. 70, 2855-2858 (2005).

41. Sarda, S. R. et al. An efficient protocol for the synthesis of 2-amino-4, 6diphenylpyridine-3-carbonitrile using ionic liquid ethylammonium nitrate. ARKIVOC xvi, 43-48 (2006).

42. Zhou, C., Dubrovsky, A. V. \& Larock, R. C. Diversity-oriented synthesis of 3 iodochromones and heteroatom analogues via ICl-induced cyclization. J. Org Chem. 71, 1626-1632 (2006). 
43. Yang, Q. \& Alper, H. Synthesis of chromones via palladium-catalyzed ligand-free cyclocarbonylation of $o$-iodophenols with terminal acetylenes in phosphonium salt ionic liquids. J. Org. Chem. 75, 948-950 (2010).

44. Chai, G., Qiu, Y., Fu, C. \& Ma, S. Efficient assembly of chromone skeleton from 2,3-allenoic acids and benzynes. Org. Lett. 13, 5196-5199 (2011).

45. Sashidhara, K. V., Kumar, M. \& Kumar, A. A novel route to synthesis of flavones from salicylaldehyde and acetophenone derivatives. Tetrahedron Lett. 53, 2355-2359 (2012).

46. Nam, D. H. et al. Design and synthesis of 4-quinolinone 2-carboxamides as calpain inhibitors. Bioor. Med. Chem. Lett. 18, 205-209 (2008).

47. Lu, C. et al. Identification of small-molecule antagonists of the Pseudomonas aeruginosa transcriptional regulator PqsR: biophysically guided hit discovery and optimization. Chem. Bio. 19, 381-390 (2012).

48. Biswas, K. et al. Discovery of potent, orally bioavailable phthalazinone bradykinin B1 receptor antagonists. J. Med. Chem. 54, 7232-7246 (2011).

49. Palani, T., Park, K., Song, K. H. \& Lee, S. Palladium-catalyzed synthesis of (Z)-3arylthioacrylic acids and thiochromenones. Adv. Synth. Catal. 355, 1160-1168 (2013).

50. Klier, L., Bresser, T., Nigst, T. A., Karaghiosoff, K. \& Knochel, P. Lewis acidtriggered selective zincation of chromones, quinolones, and thiochromones: application to the preparation of natural flavones and isoflavones. J. Am. Chem. Soc. 134, 13584-13587 (2012).

51. Koh, A. L. et al. Energy-Loss Spectroscopy (EELS) of surface plasmons in single silver nanoparticles and dimers: influence of beam damage and mapping of dark modes. ACS Nano 3, 3015-3022 (2009).

52. Aguirre, M. H., Shkabko, A. \& Weidenkaff, A. Microwave plasma nitridation of $\mathrm{SrTiO}_{3}$ : a quantitative EELS, TEM, and STEM-HAADF analysis of the $\mathrm{SrTiO}_{3-\mathrm{x}} \mathrm{N}_{\mathrm{y}}$ growth and the structural evolution. Crystal Growth \& Design 10, 3562-3567 (2010).

53. Moorthy, S. K. E., Rousseau, O., Viret, M. \& Kociak, M. Nanoscale chemical and structural characterization of transient metallic nanowires using aberrationcorrected STEM-EELS. Nano Lett. 12, 2732-2739 (2012).

54. Kadkhodazadeh, S. et al. Scaling of the surface plasmon resonance in gold and silver dimers probed by EELS. J. Phys. Chem. C 118, 5478-5485 (2014).

55. Schladt, T. D., Graf, T. \& Tremel, W. Synthesis and characterization of monodisperse manganese oxide nanoparticles-evaluation of the nucleation and growth mechanism. Chem. Mater. 21, 3183-3190 (2009).
56. Meyer, K., Bendix, J., Metzler-Nolte, N., Weyhermuller, T. \& Wieghardt, K Nitridomanganese(V) and -(VI) complexes containing macrocyclic amine ligands. J. Am. Chem. Soc. 120, 7260-7270 (1998).

57. Dediu, V. et al. SQUID measurement of the verwey transition on epitaxial (100) magnetite thin films. J. Magn. Magn. Mater. 316, 721-723 (2007).

\section{Acknowledgments}

The authors gratefully acknowledge financial supports of DST (project no. SR/NM/NS-29/ 2010, SR/S5/GC-04/2012 and SR/S1/OC-05/2012) and CRNN, India and research fellowships from CSIR, India.

\section{Author contributions}

Major work was done by S.K. and Y.S. S.K., Y.S., R.M.L., S.G. and K.M. were contributed in synthesizing and characterizing the molecules, manuscript preparation, discussion on chemistry involved, and commenting on the manuscript.

\section{Additional information}

Supplementary information accompanies this paper at http://www.nature.com/ scientificreports

Competing financial interests: The authors declare no competing financial interests.

How to cite this article: Khamarui, S., Saima, Y., Laha, R.M., Ghosh, S. \& Maiti, D.K.M. Functionalised $\mathrm{Mn}^{\mathrm{VI}}$-nanoparticles: an advanced high-valent magnetic catalyst. Sci. Rep. 5, 8636; DOI:10.1038/srep08636 (2015).

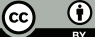

This work is licensed under a Creative Commons Attribution 4.0 International License. The images or other third party material in this article are included in the article's Creative Commons license, unless indicated otherwise in the credit line; if the material is not included under the Creative Commons license, users will need to obtain permission from the license holder in order to reproduce the material. To view a copy of this license, visit http://creativecommons.org/licenses/by/4.0/ 